\title{
MX Stage Finding
}

National Cancer Institute

\section{Source}

National Cancer Institute. MX Stage Finding. NCI Thesaurus. Code C48704.

A distant metastasis TNM finding indicating that the status of distant metastasis cannot be assessed. 